\title{
Pituitary Adenylate Cyclase Activating Peptide (PACAP) in the Retinohypothalamic Tract: A Daytime Regulator of the Biological Clock ${ }^{a}$
}

\author{
JENS HANNIBAL ${ }^{b, g}$ JIAN M. DING,${ }^{c}$ DONG CHEN,${ }^{d}$ JAN \\ FAHRENKRUG,${ }^{b}$ PHILIP J. LARSEN, ${ }^{e}$ MARTHA U. GILLETTE,,$d$ \\ AND JENS D. MIKKELSEN ${ }^{f}$ \\ ${ }^{b}$ Department of Clinical Biochemistry, Bispebjerg Hospital, University \\ of Copenhagen, DK-2400 Copenhagen NV, Denmark \\ ${ }^{c}$ Department of Cell \& Structural Biology and ${ }^{d}$ Molecular and \\ Integrative Physiology, University of Illinois, Urbana, Illinois USA \\ ${ }^{e}$ Institute of Medical Anatomy, University of Copenhagen, Denmark \\ ${ }^{f}$ Department of Neurobiology, Research and Development, H. Lundbeck \\ A/S, Valby Copenhagen, Denmark
}

\begin{abstract}
The retinohypothalamic tract (RHT) relays photic information from the eyes to the brain biological clock in the suprachiasmatic nucleus (SCN). Activation of this pathway by light plays a role in adjusting circadian timing to light exposure at night. Here we report a new signaling pathway by which the RHT regulates circadian timing in the daytime as well. Using dual-immunocytochemistry for PACAP and the in vivo tracer Cholera toxin subunit $\mathrm{B}(\mathrm{ChB})$, intense PACAP immunoreactivity (PACAP-IR) was observed in retinal afferents at the rat SCN as well as in the intergeniculate leaflet (IGL) of the thalamus. This PACAP-IR was nearly lost upon bilateral eye enucleation. PACAP afferents originated from ganglion cells distributed throughout the retina. The phase of circadian rhythm measured as SCN neuronal activity in vitro was significantly advanced by application of PACAP-38 during the subjective day, but not at night. The effect is channelled to the clock via a PACAP 1 receptor-cAMP signaling mechanism. Thus, in addition to its role in nocturnal regulation by glutamatergic neurotransmission, the RHT can adjust the biological clock by a PACAP-cAMP-dependent mechanism during the daytime.
\end{abstract}

$\mathrm{M}$ ammalian circadian rhythms are generated by an endogenous circadian clock in the suprachiasmatic nucleus (SCN) of the hypothalamus. ${ }^{1-5}$ The timing of the circadian clock is adjusted daily by the environmental light:dark cycle via the retinohypothalamic tract (RHT), a direct neural projection from the retina to the SCN.${ }^{6,7}$ Exposure to light in their subjective night can reset the animal's phase of circadian rhythms. ${ }^{8,9}$ These light-induced phase shifts involve the release of glutamate from the RHT terminals in the SCN and subsequent activation of NMDA receptor, calcium influx, and nitric oxide signaling pathway. ${ }^{9-13}$

${ }^{a}$ This study was supported by the DanishMRC (12-1642), Danish Biotechnology program for Cellular Communication, PHS (USA) grant NS22155 from NINDS (M. U. G.).

${ }^{g}$ Corresponding author: Jens Hannibal; Phone 45353126 46; Fax: 453531 3955; E-mail: biochbbh@inet.uni2.dk 
Arousal or exposure to a dark pulse in the subjective day can phase-shift the animal's circadian rhythm. ${ }^{14,15}$ The dark pulse-induced phase shift in the daytime involves the release of neuropeptide Y (NPY) from the intergeniculate leaflet (IGL) of the thalamus through a secondary pathway known as the geniculohypothalamic tract (GHT). ${ }^{16-18}$ It has long been known that daytime phase-shifting involves the activation of a cAMP signaling pathway within the SCN. ${ }^{19}$ However, the primary neurotransmitter mediating daytime phase shifts through cAMP is not yet known.

Pituitary adenylate cyclase activating peptide (PACAP) is a new member of the vasoactive intestinal peptide/secretin/glucagon family. It exists in two forms, PACAP-27 and PACAP-38, and is a powerful stimulator of adenylate cyclase. ${ }^{20,21}$ It has been demonstrated in a high concentration in neuroendocrine areas in mammals, suggesting a role as a hypothalamic regulatory peptide, but has also been found to be distributed throughout the brain though in smaller concentrations. ${ }^{22,23}$ PACAP-38 is the dominant product of posttranscriptional processing of the PACAP precursor in the brain. ${ }^{22}$

The endogenous transmitter activating cAMP in the SCN has not been established. The present study provides evidence that PACAP may be such a factor.

\section{MATERIALS AND METHODS}

\section{Immunocytochemistry}

On the day of fixation, the animals were anesthetized with tribromoethanol $(20 \mathrm{mg} / 100$ $\mathrm{g}$ body weight) and perfused via the left ventricle with a room temperature solution of saline $(0.9 \%)$ to which heparin $(15,000 \mathrm{IU} / \mathrm{l})$ was added $(75-100 \mathrm{ml}$ over $3 \mathrm{~min})$. This perfusion was followed by $2 \%$ paraformaldehyde, $0.2 \%$ picric acid in $0.1 \mathrm{M}$ sodium phosphate buffer, $\mathrm{pH} 7.2$ (300 $\mathrm{ml}$ over $15 \mathrm{~min})$. After fixation, the brains were rapidly removed and postfixed in the same fixative for $24 \mathrm{~h}$. After postfixation, the brains were equilibrated in phosphate-buffered saline (PBS, $0.05 \mathrm{M}, \mathrm{pH} 7.4$ ) containing $30 \%$ sucrose for $48 \mathrm{~h}$ at $4^{\circ} \mathrm{C}$ and then sectioned in a freezing microtome into $40 \mu \mathrm{m}$ sections. Whole mounts of the retina were processed as the free-floating brain sections as described below. Immunocytochemical visualization of PACAP immunoreactivity (IR) was carried out as described previously using the avidin-biotin bridge method. ${ }^{22}$ The sections and the entire retina whole-mounts were incubated for $24 \mathrm{~h}$ with a monoclonal anti-PACAP antibody at $4^{\circ} \mathrm{C}$. The specificity of the monoclonal antibody (code MabJHH1) has been characterized previously and displays equal affinity for PACAP-38 and PACAP-27, recognizing an epitope between amino acid 6-16, but has no affinity for structurally related peptides such as VIP. ${ }^{22}$ Control sections for single antigen immunocytochemistry were routinely processed by either omitting or replacing the primary antibody with an equivalent concentration of either goat or rabbit preimmune serum or with antibody preabsorbed with PACAP-38 and PACAP-27 $(20 \mu \mathrm{g} / \mathrm{ml})$. Using these procedures, all immunocytochemical staining was blocked. Immunocytochemical visualization of PACAP-IR and ChB was performed by the procedure described previously for visualization of two antigens ${ }^{24}$ using a mixture of monoclonal PACAP-antibody (supernatant diluted 1:2) and goat anti-ChB antiserum (List Biologicals, Campbell, CA) (diluted 1:750) for $24 \mathrm{~h}$ at $4^{\circ} \mathrm{C}$.

\section{In Situ Hybridization Histochemistry}

In situ hybridization was performed using a slight modification of the previously described procedure. ${ }^{25} 12-\mu \mathrm{m}$ sections from three rats were used. The ${ }^{35} \mathrm{~S}$-UTP-labeled antisense and sense RNA probes were prepared by in vitro transcription using T7 
(antisense) and SP6 (sense) RNA polymerase. The template containing a cDNA encoding the whole PACAP type I receptor sequence (nucleotide 20-1546) ${ }^{26}$ was kindly given by Dr. Steven A. Wank. The plasmid (pGEM-3Z) was linearized with $H$ indIII for antisense probe and with EcoRI for the sense probe. Transcription was performed at $37^{\circ} \mathrm{C}$ for $2 \mathrm{~h}$ in $20 \mu \mathrm{l}$ containing $5 \times$ TB buffer (Boehringer Mannheim, Germany), 25 mM dithiothreitol (DTT), 20 U RNasin (Amersham, DK), 1.5 mM NTPmix (Boehringer Mannheim, Germany), 40 U polymerase (T7; Stratagene, USA or SP6; Boehringer Mannheim, Germany), and $2 \mu \mathrm{M}{ }^{35} \mathrm{~S}$-UTP $(3,000 \mathrm{mCi}$, Amersham, DK). After removal of the DNA template by adding $1 \mu \mathrm{l}$ RNasin (30-40 units), $2 \mu 1$ tRNA $(10 \mu \mathrm{g} / \mu \mathrm{l})$, and $1 \mu \mathrm{l}$ DNase (Boehringer Mannheim, Germany), and incubation for further $15 \mathrm{~min}$ at $37^{\circ} \mathrm{C}$, the probes were purified by water/phenol extraction followed by chloroform/isoamyl alcohol extraction, and finally, $\mathrm{NH}_{4}$ acetate/ethanol precipitation. The labeled product was fragmented by incubation in hydrolysis buffer for $50 \mathrm{~min}$ at $60^{\circ} \mathrm{C}$ and used in a concentration of $1 \times 10^{7} \mathrm{cpm} / \mathrm{ml}$. After hybridization overnight at $53^{\circ} \mathrm{C}$, the sections were washed in $4 \times$ saline sodium citrate $(4 \times \mathrm{SSC}=$ $0.60 \mathrm{M} \mathrm{NaCl}, 0.060 \mathrm{M}$ sodium citrate), $4 \mathrm{mM}$ DTT for a few minutes at room temperature followed by RNase treatment for $30 \mathrm{~min}$ (RNase A buffer, Sigma, USA). After washing in $2 \times \mathrm{SSC}, 2 \mathrm{mM}$ DDT at room temperature for $60 \mathrm{~min}$ followed by washing in $0.01 \times \mathrm{SSC}, 2 \mathrm{mM}$ DDT at $60^{\circ} \mathrm{C}$ for $60 \mathrm{~min}$ and $1 \times \mathrm{SSC}, 2 \mathrm{mM}$ DDT for $10 \mathrm{~min}$ at room temperature, the sections were dehydrated through a series of alcohols. The slides were finally exposed to Amersham Hyperfilm for three weeks. For control purposes, hybridization was performed in parallel using an antisense and a sense probe on consecutive sections.

\section{SCN Brain Slice and Neurophysiological Methods}

These methods have been described in detail previously. ${ }^{9}$ Briefly, a $500 \mu \mathrm{m}$ coronal hypothalamic slice containing the paired SCN was prepared at least $2 \mathrm{~h}$ before the onset of the dark phase from 6- to 9-week-old inbred Long-Evans rats housed in a 12-h light: 12-h dark lighting schedule. Brain slices survived for three days with continuous perfusion $(34 \mathrm{ml} / \mathrm{h}$ ) by Earle's balanced salt solution (EBSS), supplemented with $24.6 \mathrm{mM}$ glucose, $26.2 \mathrm{mM}$ sodium bicarbonate, and $5 \mathrm{mg} / \mathrm{l}$ of gentamicin and saturated with $95 \% \mathrm{O}_{2} ; 5 \%$ $\mathrm{CO}_{2}$ at $37^{\circ} \mathrm{C}(\mathrm{pH} 7.4)$. The single unit activity of SCN neurons was recorded extracellularly with a glass microelectrode, and running means were calculated to determine the peak of activity. Effects of $10^{-6} \mathrm{M}$ PACAP-38 (Sigma, St. Louis, USA), the dominant product of posttranscriptional processing of the PACAP precursor in the rat brain, ${ }^{22}$ were examined at circadian time (CT) 6,14, and 19. For treatments, the perfusion was stopped and a $1.0 \mu \mathrm{l}$ microdrop of test substance dissolved in EBSS was applied directly to the SCN. After $10 \mathrm{~min}$, the SCN surface was washed with EBSS, perfusion was resumed, and the time of peak was assessed on the subsequent days. Extracellular single unit activities were sampled throughout the SCN in brain slice in $10 \mathrm{sec}$ intervals over $2 \mathrm{~min}$ and grouped into a $2 \mathrm{~h}$ running average to determine the peak of firing activity. ${ }^{9}$ Because a PACAP/VIP-R2 receptor has been demonstrated in the $\mathrm{SCN},{ }^{27}$ we evaluated effects of VIP at the time of maximal SCN sensitivity to PACAP. Dose-response curves were generated at CT 6 by applying PACAP-38 at a dose from $10^{-10} \mathrm{M}$ to $10^{-5} \mathrm{M}$ or VIP from $10^{-7} \mathrm{M}$ to $10^{-4} \mathrm{M}$ for a 10 -min pulse in a $1 \mu \mathrm{l}$ droplet. For each dose, three to four experiments were performed. To investigate the specificity of the PACAP effect as well as the signaling pathway involved, a PACAP antagonist PACAP $6-38^{28}(10 \mu \mathrm{M})$ and a competitive inhibitor for cAMP-dependent processes, Rp-cAMPS $(\mathrm{Rp})^{29}(10 \mu \mathrm{M})$, were added to EBSS $20 \mathrm{~min}$ before PACAP-38 was applied. Experiments were performed with the experimenter "blind" to the treatment protocol. 


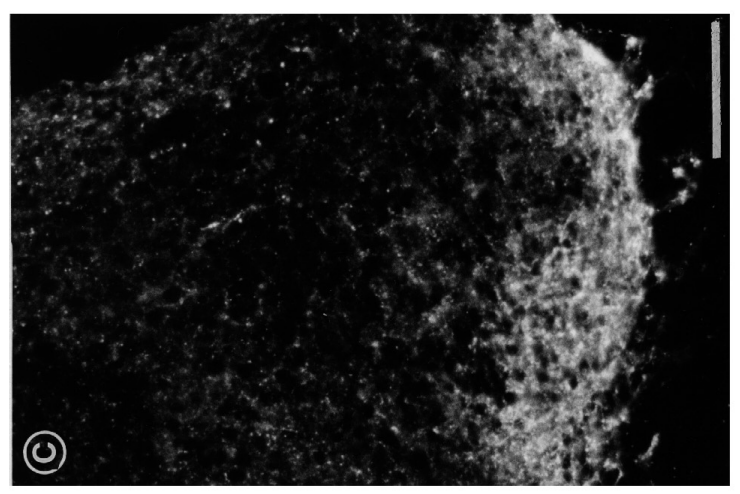

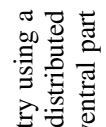

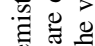

気

궁

응

苛总句

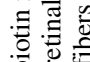

要

言党

융

氙充

这导

䓂

$\stackrel{*}{*}$

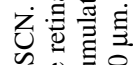

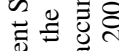

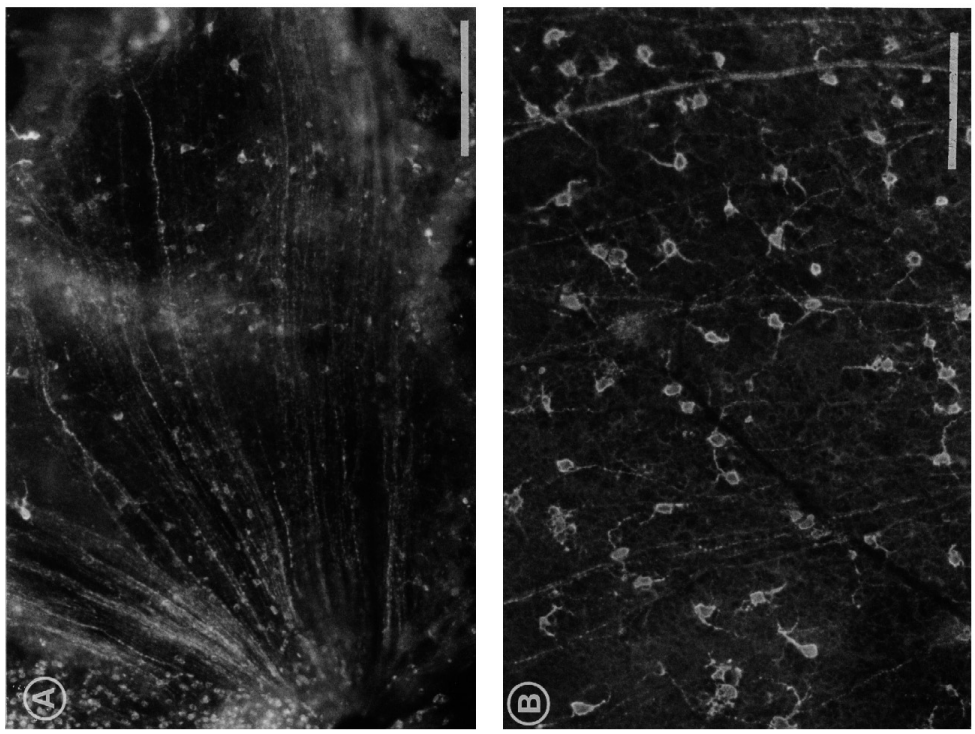

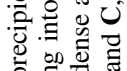

에

एँ

๖ ¿

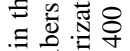

क⿺⿻一𠃋十乚丶

है을

.$\Xi \cdot \frac{0}{0}$

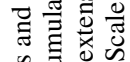

过造

ธี สี పี

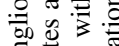

总

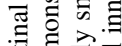

可 词

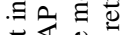

苞䓕怘

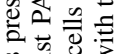

글

충

论

约吾导

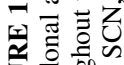

疋은 


\section{RESULTS AND DISCUSSION}

Using immunocytochemistry we showed PACAP-IR fibers coursing towards the retinal papil (FIG. 1,A), in retinal ganglion cells (FIG. 1,B), and in nerve fibers and terminals in the ventrolateral part of the SCN (FIG. 1,C) of adult rats. The exact position of PACAP terminals in the SCN varied along the rostroventral axis of the SCN, but overlapped entirely with the retinorecipient area. In the rostral SCN, the PACAP-IR nerve fibers were located in the extreme ventral part of the nucleus, whereas in the middle and caudal SCN, the location changed to a more lateral and dorsal position. The retinal ganglion cells projecting to the circadian system originate from a distinct subset of neurons spread throughout the retina. ${ }^{30,31}$ Ganglion cells expressing PACAP-IR were frequent (FIG. 1,B) and seemed to represent a population of small neurons with a few branching processes. They were widely distributed
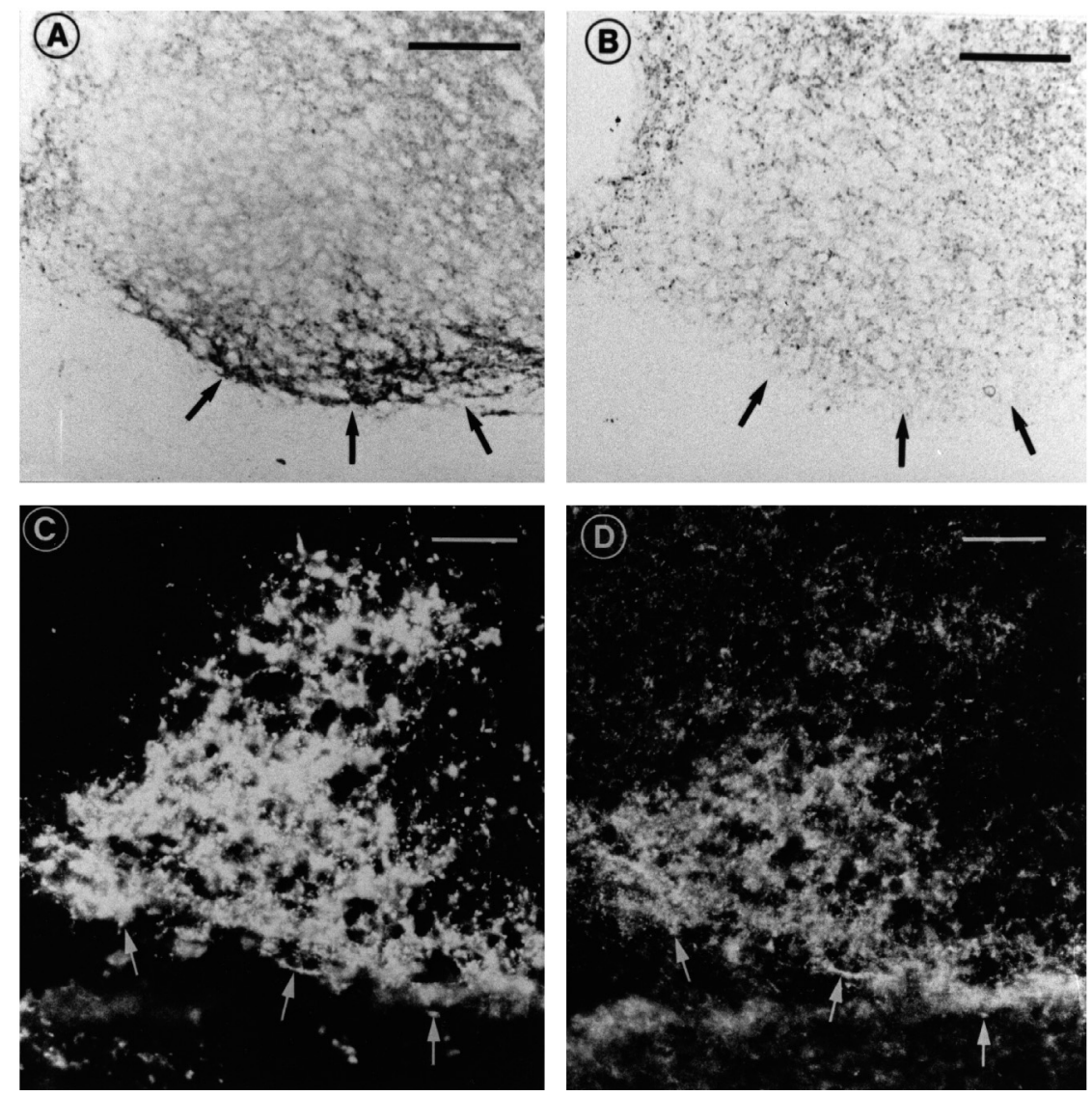

FIGURE 2. PACAP is present in the RHT. A high accumulation of PACAP-IR nerve fibers is present in the ventral SCN (A), but this is dramatically reduced by enucleation (B). Dual immunocytochemistry showing the distribution of $\mathrm{ChB}(\mathbf{C})$ and PACAP-IR (D). The arrows point to positive elements that contain both ChB- and PACAP-IR. Scale bars A-D, $100 \mu \mathrm{m}$. 
in the retina and likely belong to the subset of ganglion cells of the W-type characterized by their capacity to transport viral tract tracers from the eye to the circadian system. ${ }^{30,31}$ To determine the extent of labeling due to retinal innervation, PACAP distribution was studied in normal and bilaterally enucleated rats. In the enucleated animals PACAP-IR nerve fibers in the SCN were greatly diminished. In particular, prominent reduction was observed in the retinorecipient area of enucleated animals (FIG. 2,A and B). The nerve fibers originate from the ganglion cells, since intraocular injections of $\mathrm{ChB}$ and concomitant visualization of PACAP-IR and ChB in the SCN revealed that the majority of PACAP-IR nerve fibers also exhibited ChB-IR (FIG. 2,C and D). However, detectable levels of immunoreactivity were still found in the SCN after enucleation, indicating that a minor afferent system may originate from the brain. Notably, the IGL also contained a considerable plexus of PACAP-IR nerve fibers and varicose terminals, which overlapped extensively with the distribution of retinal afferents and disappeared after enucleation (not shown).

At present, three types of receptors with affinity for PACAP have been characterized and cloned, ${ }^{27,32-34}$ some of which also have affinity for VIP. The PACAP type 1 receptor, which is specific for PACAP, activates cAMP and inositol triphosphate (IP-3) pathways, depending upon the splice variant.$^{34}$ The PACAP type 2 (VIP type 1 and VIP type 2 ) receptors show similar affinities for VIP and PACAP, and are coupled to cAMP. Since the PACAP/VIP type 2 receptor mRNA is confined to the dorsal SCN, ${ }^{27,32,33}$ it is unlikely to be regulated directly by the retinal afferents. We found here that the PACAP-R1 mRNA is located in the ventral SCN (FIG. 3) indicating that the PACAP-R1 on the SCN cells could be primarily affected by the PACAP afferents from the retina.

In order to determine the functional implications of PACAP innervation of the SCN, the effect of PACAP-38 on the phasing of SCN rhythm of neuronal activity was assessed. Application of PACAP-38 could alter the phase of the circadian rhythm of neuronal activity (FIG. 4,A). The phase shift occurred as a prominent advance of the activity peak by 3.5 $\mathrm{h} \pm 0.4 \mathrm{~h}$ when PACAP-38 was applied in a $1 \mu \mathrm{l}$ drop at CT6, mid subjective day. The CT

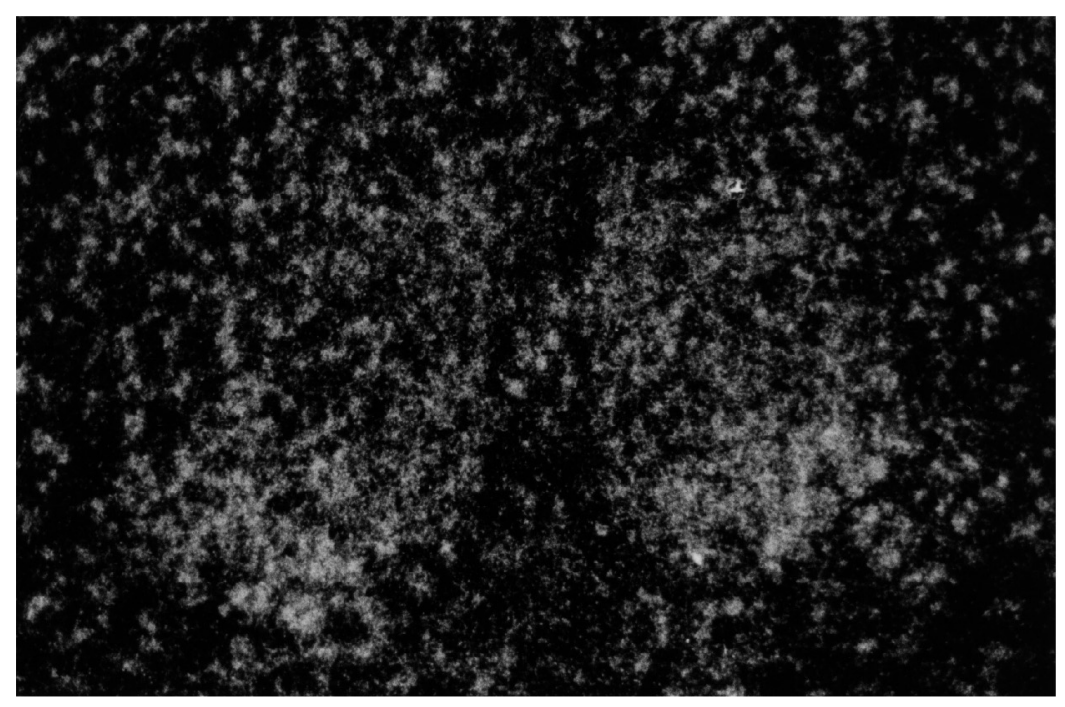

FIGURE 3. A high accumulation of PACAP-R1 mRNA is present in the SCN using a cRNA antisense probe. 
0 is defined as the time when light comes on in the donor colony. This effect was dose dependent, with a half-maximum shift occurring in response to a microdrop of $5 \times 10^{-9} \mathrm{M}$ of PACAP-38. Notably, the $1 \mu \mathrm{l}$ drop of PACAP-38 may be significantly diluted by diffusion into the SCN. Thus, the effective concentration would be in the range seen in different binding assays of PACAP receptors. ${ }^{26}$ Interestingly, the effect could only be produced at CT6, but not at CT14 or CT19 (FIG. 4,C). This pattern is in antiphase to the timing of clock sensitivity to light, glutamate, NMDA receptor activation, NO donors, and the transcriptional factors CREB and Fos. ${ }^{11,35}$ However, it is overlapping with SCN sensitivity to cAMP, serotonin, and NPY. ${ }^{19,29,36-39}$ To examine whether the PACAP-selective type-1
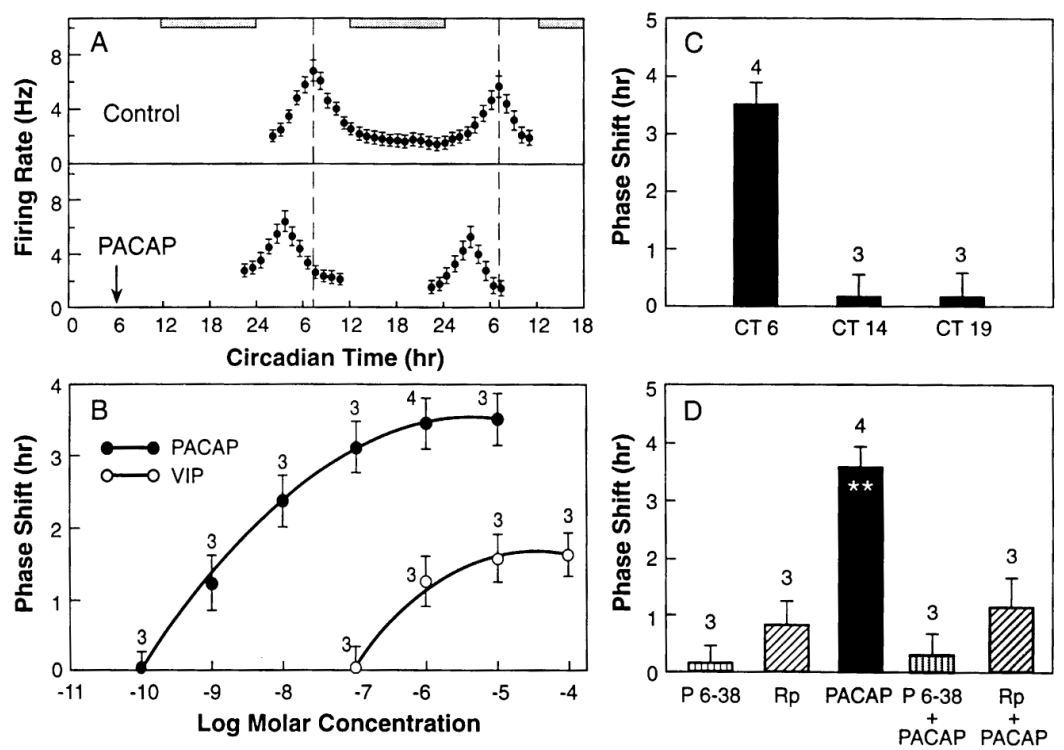

FIGURE 4. (A) PACAP directly resets the phase of the SCN circadian rhythm of neuronal activity. (Top panel) Circadian rhythms of neuronal activity of the SCN in brain slice recorded from 112 units over $38 \mathrm{~h}$ under constant conditions in vitro. The rhythm peaked in mid-subjective day at CT7, on both day 2 and 3 in vitro. (Bottom panel) Effect of PACAP applied at CT6 advanced the peak of the SCN activity rhythm by $3.5 \mathrm{~h}$. A $1 \mu 1$ droplet of $1 \times 10^{-6}$ M PACAP- 38 was directly applied to the $\mathrm{SCN}$ for $10 \mathrm{~min}$, followed by rinsing in medium. Horizontal bars indicate subjective night. (B) Doseresponse curve for a 10-min pulse of $1 \mu 1$ of PACAP-38 (closed circles) and VIP (open circles) to the $\mathrm{SCN}$ in vitro at CT 6 . Each data point represents the mean \pm SD of three to four experiments, as indicated, measuring the time-of-peak as in FIG. 3 (A). Half-maximal response was achieved at $3 \times 10^{-9}$ M PACAP and $7 \times 10^{-7} \mathrm{M}$ VIP. Experiments were performed with the experimenter "blind" to the treatment protocol. (C) Phase advance by PACAP depends on the circadian time of application to the $\mathrm{SCN}$ (dosage as in FIG. 4,A). Each data point represents three to four experiments as indicated. Phase advance is $3.5 \pm 0.4 \mathrm{~h}$ at CT 6 . No significant phase shift was detected at CT 14 or CT 19, points of maximal responsiveness to light and glutamate. ${ }^{9}$ (D) The phase shift by PACAP was blocked by the PACAP receptor antagonist PACAP 6-38, and a competitive inhibitor for cAMP-dependent processes, Rp-cAMPS. Brain slices were incubated for 20 min with $10 \mu \mathrm{M}$ PACAP 6-38 or $10 \mu \mathrm{M}$ Rp-cAMPS before PACAP application in a microdrop onto the SCN for 10 min. Each data point represents the mean \pm SD of three to four experiments as indicated. Significant difference was found between PACAP-treated vs. Rp-cAMPS-treated groups, and between groups treated with PACAP and PACAP 6-38 + PACAP and Rp-cAMPS + PACAP, respectively. No significant difference was detected between PACAP 6-38, Rp-cAMPS, and antagonist + PACAP-treated groups. (** $p \leq 0.01$ ) 
receptor mediates phase resetting of the biological clock, we investigated the effects of VIP in vitro, since a PACAP/VIP-R2 receptor, which has equal affinities for both PACAP and VIP, had also been demonstrated in the SCN. ${ }^{27}$ Therefore, we examined the response to VIP over a range of concentrations. VIP was 1,000 -fold less potent than PACAP at altering the phasing of the SCN circadian rhythm. The half-maximal response to VIP was calculated as a $0.75 \mathrm{~h}$ phase advance to a microdrop containing $7 \times 10^{-7} \mathrm{M}$ VIP. As can be seen in Figure 4, B, a shift of this magnitude would be produced by $7 \times 10^{-10} \mathrm{M}$ PACAP. To investigate the second messenger pathway activated by PACAP, we tested the effect of PACAP together with a competitive inhibitor for cAMP-dependent processes, Rp-cAMPS. Application of Rp-cAMPS before PACAP application completely blocked the phase advance of PACAP at CT 6 (FIG. 4, D), confirming that the PACAP-R1 receptor stimulates a second messenger pathway involving cAMP/protein kinase A.

We have shown that PACAP is located in the RHT and that the peptide adjusts the phase of SCN through a PACAP-R1 receptor located in the ventral SCN. It is striking that SCN sensitivity to PACAP-38 lies in the subjective day, a time when light stimuli would normally activate the RHT. Yet, light by itself does not cause phase shifting in the daytime. Arousal stimuli, such as dark pulses and intense locomotor activity, do induce daytime phase advances, and NPY release from the GHT is essential for generation of this type of phase shift. ${ }^{29,38,39}$ Additionally, serotonin (5-hydroxytryptamine; 5-HT) induces significant phase advances at the time PACAP is effective. ${ }^{36}$ Activation of a 5- $\mathrm{HT}_{7}$ receptor, which is coupled to cAMP stimulation, is required for this shift, but mRNA for this receptor has not been demonstrated in the $\mathrm{SCN} .{ }^{40}$ Based on the present findings it is possible that serotonin may act through presynaptic receptors on RHT terminals and thereby stimulate a selective release of PACAP, activate the PACAP-R1 receptor, and stimulate cAMP pathways within the SCN. Localization of PACAP-IR in the retinal afferents, where NPY and serotonin projections terminate, suggests that integration of the geniculate and raphe signals may occur presynaptically at the PACAP-containing boutons. This may provide the intense stimulation for mobilization of peptide release into the synapse and may underlie the lack of effect of light alone in the daytime. The localization of PACAP-R1 mRNA and the profound involvement of cAMP in SCN phase advances suggest that PACAP exerts its effect postsynaptically. Both cAMP and nonphotic stimuli have phase-shifting capacities during the subjective day, and this sensitivity is regulated downstream from cAMP activation within the cells of the SCN..$^{14,15}$ The phase shift exerted by PACAP during the subjective day, if associated with arousal, is not transmitted through expression of the transcriptional factor Fos. Another regulatory path could be through a cAMP-dependent cascade that involves expression of inducible cyclic AMP early repressor (ICER) mRNA. ${ }^{41,42}$

\section{REFERENCES}

1. Turek, F. W. 1985. Circadian neural rhythms in mammals. [Review]. Ann. Rev. Physiol. 47: 49-64.

2. Hastings, M. H. 1991. Neuroendocrine rhythms. Pharmac. Ther. 50: 35-71.

3. Klein, D. C., R. Y. Moore \& S. M. Reppert. 1991. Suprachiasmatic Nucleus. The Mind's Clock. Oxford University Press. New York.

4. Harrington, M. E., B. RusaK \& R. E. Mistlberger. 1994. Anatomy and physiology of the mammalian circadian system. In Principles and Practice of Sleep Medicine. M. H. Kryger, T. Roth \& W. C. Dement, Eds.: 286-301. W.B. Saunders Company. Philadelphia.

5. MoRIN, L.P. 1994. The circadian visual system. [Review]. Brain Res. Rev. 19: 102-127.

6. Moore, R. Y. \& N. J. LenN.1972. A retinohypothalamic projection in the rat. J. Comp. Neurol. 146: $1-14$

7. Johnson, R. F., R. Y. MoORE \& L. P. Morin. 1988. Loss of entrainment and anatomical plasticity after lesions of the hamster retinohypothalamic tract. Brain Res. 460: 297-313.

8. Takahashi, J. S., P. J. Decoursey, L. Bauman et al. 1984. Spectral sensitivity of a novel photoreceptive system mediating entrainment of mammalian circadian rhythms. Nature 308: $186-188$. 
9. Ding, J. M., D. ChEN, E. T. WeBER et al. 1994. Resetting the biological clock: mediation of nocturnal circadian shifts by glutamate and NO. Science 266: 1713-1717.

10. CAstel, M., M. BelenKy, S. Cohen et al. 1993. Glutamate-like immunoreactivity in retinal terminals of the mouse suprachiasmatic nucleus. Eur. J. Neurosci. 5: 368-381.

11. Rea, M. A., B. Buckley \& L. M. Lutton. 1993. Local administration of EAA antagonists blocks light-induced phase shifts and c-fos expression in hamster SCN. Am. J. Physiol. 265: R1191-R1198.

12. Mikkelsen, J. D., P. J. Larsen \& F. J. Ebling. 1993. Distribution of N-methyl D-aspartate (NMDA) receptor mRNAs in the rat suprachiasmatic nucleus. Brain Res. 632: 329-333.

13. Mikkelsen, J. D., P. J. Larsen, G. Mick et al. 1995. Gating of retinal inputs through the suprachiasmatic nucleus: role of excitatory neurotransmission. Neurochem. Int. 27: 263-272.

14. Mrosovsky, N. \& P. A. SAlomon. 1987. A behavioral method for accelerating re-entrainment of rhythms to new light-day cycles. Nature 330: 372-373.

15. Sumova, A., F. J. Ebling, E. S. MaYwood et al. 1994. Non-photic circadian entrainment in the Syrian hamster is not associated with phosphorylation of the transcriptional regulator CREB within the suprachiasmatic nucleus, but is associated with adrenocortical activation. Neuroendocrinol. 59: 579-589.

16. Harrington, M. E., D. M. NANCE \& B. Rusak. 1985. Neuropeptide Y immunoreactivity in the hamster geniculo-suprachiasmatic tract. Brain. Res. Bull. 15: 465-472.

17. CARD, J. P. \& R. Y. MoORE . 1989. Organization of lateral geniculate-hypothalamic connections in the rat. J. Comp. Neurol. 284: 135-147.

18. MikKelsen, J. D. 1990. Projections from the lateral geniculate nucleus to the hypothalamus of the Mongolian gerbil (Meriones unguiculatus): an anterograde and retrograde tracing study. J. Comp. Neurol. 299: 493-508.

19. Prosser, R. A. \& M. U. Gillette. 1989. The mammalian circadian clock in the suprachiasmatic nuclei is reset in vitro by cAMP. J. Neurosci. 9: 1073-1081.

20. MiYATA, A., A. A. ARIMURA, R.R. DAhl et al. 1989. Isolation of a novel 38 residue-hypothalamic polypeptide which stimulates adenylate cyclase in pituitary cells. Biochem. Biophys. Res. Commun. 164: 567-574.

21. ARimura, A. \& S. ShiODA. 1995. Pituitary adenylate cyclase activating polypeptide (PACAP) and its receptors: neuroendocrine and endocrine interaction. Front. Neuroendocrinol. 16: 53-88.

22. Hannibal, J., J. D. MikKelsen, H. Clausen et al. 1995. Gene expression of pituitary adenylate cyclase activating polypeptide (PACAP) in the rat hypothalamus. Regul. Pept. 55: 133-148.

23. MikKelsen, J. D., J. HANNibal, J. FAhrenkrug et al. 1995. Pituitary adenylate cyclase activating peptide-38 (PACAP-38), PACAP-27, and PACAP related peptide (PRP) in the rat median eminence and pituitary. J. Neuroendocrinol. 7: 47-55.

24. Hannibal J., J. D. MikKelsen, J. Fahrenkrug et al. 1995. Pituitary adenylate cyclase-activating peptide gene expression in corticotropin-releasing factor-containing parvicellular neurons of the rat hypothalamic paraventricular nucleus is induced by colchicine, but not by adrenalectomy, acute osmotic, ether, or restraint stress. Endocrinology 136: 4116-4124.

25. FAHRENKRUG, J. \& J. HANNIBAL. 1996. Pituitary adenylate cyclase activating polypeptide innervation of the rat female reproductive tract and the associated paracervical ganglia: effect of capsaicin. Neuroscience 73: 1049-1060.

26. Pisegna, J. R. \& S. A. WANK. 1993. Molecular cloning and functional expression of the pituitary adenylate cyclase-activating polypeptide type I receptor. Proc. Natl. Acad. Sci. USA 90: $6345-6349$.

27. Morrow, J. A., E. M. LutZ, K. M. West et al. 1993. Molecular cloning and expression of a cDNA encoding a receptor for pituitary adenylate cyclase activating peptide (PACAP). FEBS Lett. 329: 99-105.

28. RobBerecht, P., P. Gourlet, P. De NeEF et al. 1992. Structural requirements for the occupancy of pituitary adenylate-cyclase-activating-peptide (PACAP) receptors and adenylate cyclase activation in human neuroblastoma NB-OK-1 cell membranes. Discovery of PACAP(6-38) as a potent antagonist. Eur. J. Biochem. 207: 239-246.

29. Prosser, R. A., H. C. Heller \& J. D. Miller. 1994. Serotonergic phase advances of the mammalian circadian clock involve protein kinase $\mathrm{A}$ and $\mathrm{K}^{+}$channel opening. Brain Res. 644: 67-73. 
30. CoOPER, H. M., M. Herbin \& E. Nevo. 1993. Ocular regression conceals adaptive progression of the visual system in a blind subterranean mammal. Nature 361: 156-159.

31. MoORE, R. Y., J. C. SPEH \& J. P. CARD. 1995. The retinohypothalamic tract originates from a distinct subset of retinal ganglion cells. J. Comp. Neurol. 352: 351-366.

32. Ishihara, T., R. Shigemoto, K. Mori et al. 1992. Functional expression and tissue distribution of a novel receptor for vasoactive intestinal polypeptide. Neuron 8: 811-819.

33. LuTZ, E. M., W. J. SHEWARD, K. M. WeST et al. 1993. The VIP2 receptor: molecular characterisation of a cDNA encoding a novel receptor for vasoactive intestinal peptide. FEBS Lett. 334: 3-8.

34. Spengler, D., C. Waeber, C. Pantaloni et al. 1993. Differential signal transduction by five splice variants of the PACAP receptor. Nature 365: 170-175.

35. GinTY, D. D., J. M. Kornhauser, M. A.Thompson et al. 1993. Regulation of CREB phosphorylation in the suprachiasmatic nucleus by light and a circadian clock. Science 260: 238-241.

36. Prosser, R. A., J. D. Miller \& H. C. Heller. 1990. A serotonin agonist phase-shifts the circadian clock in the suprachiasmatic nuclei in vitro. Brain Res. 534: 336-339.

37. Medanic, M. \& M. U. Gillette. 1992. Serotonin regulates the phase of the rat suprachiasmatic circadian pacemaker in vitro only during the subjective day. J. Physiol. 450: 629-642.

38. Medanic, M. \& M. U. Gillette. 1993. Suprachiasmatic circadian pacemaker of rat shows two windows of sensitivity to neuropeptide Y in vitro. Brain Res. 620: 281-286.

39. Biello, S. M., D. JANIK \& N. Mrosovsky. 1994. Neuropeptide Y and behaviorally induced phase shifts. Neuroscience 62: 273-279.

40. Lovenberg, T. W., B. M. BARON, L. De Lecea et al. 1993. A novel adenylate cyclase-activating serotonin receptor (5-HT7) implicated in regulation of mammalian circadian rhythms. Neuron 11: $449-458$

41. JANiK, D., J. D. Mikkelsen \& N. Mrosovsky. 1995. Cellular colocalization of Fos and neuropeptide $\mathrm{Y}$ in the intergeniculate leaflet after nonphotic phase-shifting events. Brain Res. 698: 137-145.

42. Stehle, J. H., M. Pfeffer, R. Kuhn \& H. W. Korf. 1996. Light-induced expression of transcription factor ICER (inducible cAMP early repressor) in rat suprachiasmatic nucleus is phase-restricted. Neurosci. Lett. 217: 169-172. 